\title{
Power struggles in football: The European Super League Project and its effects
}

\section{Futbolda güç savaşları: Avrupa Süper Ligi Projesi ve etkileri}

\section{Can Çavin Ötkan ${ }^{1}$ Tekin Çolakoğlu ${ }^{2}$}

Abstract

Purpose: In the research, it is aimed to examine the opinions of the fans about the European Super League and its effects, which were presented to the public on April 18, 2021.

Method: Case study design, one of the qualitative research methods, was used. The study group of the research was determined by purposive sampling method. The study group consists of 11 male participants from different professions, who follow the UEFA Champions League organization every competition week and sports news at least 4 days a week and are supporters of a football team. Data were collected through a semi-structured interview form and subjected to content analysis.

Results: As a result of the findings, the participants stated that although there are factors that threaten the popularity of football, it is at the top among sports branches. In addition, it was stated that it would be more appropriate for football to progress with beneficial additions rather than radical changes. The majority of the participants approached the project negatively on the grounds that the founders of the European Super League gave

\section{Özet}

Amaç: Araştırmada, 18 Nisan 2021 tarihinde kamuoyuna sunulan Avrupa Süper Ligi'ne ve etkilerine yönelik taraftar görüşlerinin incelenmesi amaçlanmaktadır.

Yöntem: Nitel araştırma yöntemlerinden durum çalışması deseni kullanılmıs ve amaçlı örnekleme yöntemi ile belirlenmiş, farklı meslek gruplarına mensup, UEFA Şampiyonlar Ligi organizasyonunu her müsabaka haftas1, spor haberlerini ise haftada en az 4 gün takip eden ve bir futbol takımının taraftarı olan 11 erkek katılımcı araştırmanın çalışma grubunu oluşturmuştur. Yarı yapilandırılmış görüşme formu araciliğ1 ile veriler toplanmış ve içerik analizine tabi tutulmuştur.

Bulgular: Elde edilen bulgular neticesinde, futbolun popülaritesini tehdit eden unsurlar olmasına rağmen spor branşları arasında zirvede yer aldığı ve köklü değişimlerden ziyade faydalı eklemelerle ilerlemenin futbol için daha uygun olacağ1 katulımcıların görüşleri doğrultusunda tespit edilmiştir. Avrupa Süper Ligi kurucularının maddi çıkarlarına öncelik verdiği ve benimsenen spor kültürüne uygun olmadiğ1 gerekçesi ile katılımcıların büyük bir çoğunluğu

\footnotetext{
${ }^{1}$ Research Assistant, Gazi University, Sport Sciences Faculty, Department of Sport Management, cancavin@gmail.com (iD) Orcid ID: 0000-0003-3800-4923

2 Assoc. Prof. Dr., Gazi University, Sport Sciences Faculty, Department of Sport Management, tcolakoglu@gmail.com (iD) Orcid ID: 0000-0002-4250-6769
} 
priority to their financial interests and that it was not suitable for the sports culture adopted. The participants stated that UEFA's reactions in this process were not convincing, and that the fans' protest actions against the project were justified. The new Champions League format and Financial Fair Play were discussed in the context of the research topic and the participants stated that these two concepts were useful but structurally lacking.

Conclusions: As a result, the process and the findings show that; It will be the most accurate and efficient strategy for both football clubs and UEFA to give priority to the opinions of the fans in the actions to be taken.

Keywords: European Super League, UEFA, football, supporter.

(Extended English summary is at the end of this document) söz konusu projeye olumsuz yaklaşım göstermişlerdir. UEFA'nın bu süreçteki tepkilerini samimi görmediklerini ifade eden futbolseverler, projeye yönelik taraftar protestolarını ise haklı bulduklarını belirtmişlerdir. UEFA'nın uygulamalarından Yeni Şampiyonlar Ligi formatı ve Finansal Fair Play, araştırma konusu bağlamında ele alınmış ve katilımcilar bu iki uygulamanın faydalı ancak yapısal olarak eksik noktalara sahip olduğunu ifade etmişlerdir.

Sonuç: Sonuç olarak, yaşanan süreç ve elde edilen bulgular göstermektedir ki; gerek futbol kulüplerinin gerek UEFA'nın atacağı adımlarda önceliklerini taraftar görüşlerine vermeleri en doğru ve verimli strateji olacaktır.

Anahtar Kelimeler: Avrupa Süper Ligi, UEFA, futbol, taraftar.

\section{Giriş}

Avrupa'da bir hayalet dolaşıyor. "The Super League” hayaleti. Futbolda bir devrim mi yoksa mevcut yapiya darbe mi?

Ölü doğan bir proje olarak değerlendirilen Avrupa Süper Ligi'nin kısa vadede hayata geçmesi mümkün gözükmüyor ancak futbol dünyasını derinden sarsmış durumda. Diğer yandan, beraberinde şiddetli tartışmaları getiren söz konusu projenin kurucu kulüpleri ile Avrupa futbolunun patronu olarak kabul edilen UEFA (Union of European Football Associations) arasında bir güç savaşının yaşanıyor olduğu da görülmekte.

Türk basınında Avrupa Süper Ligi olarak lanse edilen ve orijinal ismi ‘The Super League' olan proje, 18 Nisan 2021 tarihinde 12 adet kurucu kulüp tarafindan kamuoyuna ilan edilmiştir. Söz konusu futbol kulüpleri; AC Milan, Arsenal FC, Atlético de Madrid, Chelsea FC, FC Barcelona, FC Internazionale Milano, Juventus FC, Liverpool FC, Manchester City, Manchester United, Real Madrid CF ve Tottenham Hotspur olarak karşımıza çıkmaktadır (Davies, 2021).

Proje planlamasinda, kurucu kulüp sayısının 15'e yükseltilmesi ve sonrasında 5 futbol takımının daha lige dahil edilerek müsabakaların gerçekleştirilmesi amaçlanmıştır. Kurucu kulüplere ise JP Morgan şirketinin finansal desteğiyle ön ödeme olarak yaklaşık 3.5 Milyar Euro aktarılacağ1 belirtilmiştir. Buna ek olarak, organizasyonun Ağustos-Mayıs takvimi kapsamında hafta arası müsabakalar şeklinde ilerlemesi, kapalı lig formatına sahip olması ve katılımcı kulüplerin yerel liglerindeki organizasyonlara devam etmeleri hedeflenmiştir ('Leading European Football Clubs Announce New Super League Competition”, 2021).

Yukarıda yer alan bilgiler 1şı̆̆ında görülmektedir ki; söz konusu organizasyon, UEFA çatısı altında devam eden ve kulüpler bazındaki en popüler futbol etkinliği olarak kabul edilen Şampiyonlar Ligi'ne alternatif olarak tesis edilmiştir. Bu durum da, gerek UEFA gerek futbolun farklı paydaşları tarafından çeşitli tepkilerin ortaya çıkmasına sebebiyet vermiştir.

İlk olarak UEFA başkanı Aleksander Ceferin yapmış oluğu açıklama ile Avrupa Süper Ligi projesi gibi ayrılıkçı bir oluşumun kabul edilemez olduğunu ve projede yer alan kulüplere yerel liglerden men gibi ciddi yaptırımlar uygulanacağını belirtmiştir. Sonrasında ise İngiltere hükümeti de söz konusu oluşuma tepki göstermiş ve İngiliz kulüplerini Avrupa Süper Ligi'nden çekilmeye davet 
etmiştir. Buna ek olarak, pek çok farklı futbol kulübünün taraftarı da oluşumu ve katılan takımları protesto etmişlerdir ('Super League Clubs Will Be Held Responsible", 2021).

Avrupa Süper Ligi oluşumunun ana motivasyon kaynağının maddiyat olduğu söylenebilir. Futbolun endüstrileşme sürecinde, yıllardır süre gelen astronomik transfer harcamaları pandemi süreci ile birleşmiş ve bilhassa gelir kaybı yaşayan Avrupa'nın önde gelen kulüpleri, bu projeyi bir çıkış kapısı olarak değerlendirmişlerdir.

Real Madrid Futbol Kulübü Başkanı Florentino Perez’in açıklamaları da bu görüşü destekler niteliktedir. Perez; Avrupa'da geliri en yüksek seviyedeki futbol kulüplerinin dahi maddi anlamda zarar ettiklerini, sürdürülebilir bir ekonomik yapının olmadığını ifade etmiştir. Buna ek olarak 14-24 yaş arasındaki bireylerin futbola olan ilgilerinde ciddi bir düşüş olduğunu, UEFA Şampiyonlar Ligi organizasyonunun ise maddi getirisinin yeterli olmadığını ve çeyrek final aşamasına kadar futbolseverlerin ilgisinin düşük olduğu bir yapıya sahip olduğunu belirtmiştir (Maroto, 2021).

Diğer yandan, Perez’in ifade ettiği sürdürülebilir ekonomik yapının sağlanabilmesi adına UEFA'nın 2011 yllında yürürlüğe soktuğu Finansal Fair Play mevcuttur. Buna göre, futbol kulüplerinin gelir-gider dengelerini ve farklı parametrelerdeki harcamalarını kontrol altına almak adına belli başı kurallar bulunmaktadır. Futbol kulüplerinin; rasyonel ve disiplinli mali yapıya kavuşmasını sağlamak, kendi gelirleri temelinde faaliyet göstermeye teşvik etmek, uzun vadede sürdürülebilir yapıya sahip olmalarını sağlamak, mali yükümlülüklerini zamanında ve eksiksiz yerine getirmesini tesis etmek ve öz kaynak ve altyapı yatırımlarına uzun vadeli olarak teşvik etmek Finansal Fair Play uygulamasının ana amaçları olarak açıklanabilir (Müller, Lammert ve Hovemann, 2012).

Finansal Fair Play uygulamasının yukarıda belirtilen amaçları futbol adına gayet olumlu niyetler içerisinde olsa da ve herkes tarafindan desteklenebilir ifadeler içerse de, aksi yönde görüşler de mevcuttur. Vöpel (2013) ve Szymanski (2014), araştırmalarında, UEFA'nın Finansal Fair Play uygulamasının farklı seviyedeki futbol kulüpleri arasında pek çok açıdan eşitlik sağlamaktan uzak olduğunu belirtmişlerdir.

Bir diğer eleştirilen nokta olan UEFA Şampiyonlar Ligi’ne yönelik ilginin azaldığı iddiası için ise UEFA proaktif bir yaklaşım sergilemiş ve 2024/2025 sezonundan itibaren uygulanacak yeni Şampiyonlar Ligi formatını açıklamıştır. Buna göre; takım sayısı 32'den 36'ya çıkarılacak, 8 grup yerine tek bir grup olacak ve takımlar farklı torbalardan 10 farklı takımla müsabaka gerçekleştireceklerdir. Bu noktada, UEFA'nın yeni formatla birlikte, geniş yelpazeye sahip ve daha rekabetçi bir yapıyı amaçladığı ifade edilmektedir ('New Format for Champions League Post-2024", 2021).

Diğer yandan, UEFA'nın yayın hakları ve pazarlama gelirlerinden hak ettiklerini düşündükleri miktarda pay alamadıkları nedeniyle Avrupa futbolunun önde gelen kulüplerinin rahatsız oldukları bilinmektedir (Akşar, 2021a). Yukarıda bahsedilen yeni Şampiyonlar Ligi formatındaki artan takım sayısı nedeniyle bu payın daha da düşeceğini öngören kulüplerin, Avrupa Süper Ligi’ni cazip bir organizasyon olarak değerlendirmiş oldukları düşünülebilir.

Ancak, tüm bu gelişmelerin neticesinde Avrupa Süper Ligi hayata geçirilememiş, projeden cayan 9 kulübe UEFA, tevkifat ve zorunlu bağış gibi farklı yaptırımlar uygulayarak tekrar kendi organizasyonlarına kabul etmiştir. Real Madrid CF, FC Barcelona ve Juventus FC ise diğer 9 kurucu kulübe katılmamış ve 'The Super League' oluşumundan henüz ayrilmadıklarını belirtmişlerdir (Hill, 2021).

Özkök (2021)'ün ifadesiyle; iskambil kağıdından yapılan bir evdi ve yıkıldı mı yoksa ilerleyen dönemlerde daha güçlü bir şekilde tekrar karşımıza çıkacak mı tartışılabilir ancak şu an için Avrupa Süper Ligi projesi başarısız olmuş, UEFA'nın statükocu yaklaşımı ve bir nebze de romantik futbolseverler kazanmıştır.

Bu noktada, futbolseverlerin Avrupa Süper Ligi projesi, UEFA'nın uygulamaları ve yaşanan güç savaşlarına ilişkin görüşlerinin önem arz ettiği düşünülmekte ve bu öneme istinaden araştırlarak literatüre kazandırılması amaçlanmaktadır. 


\section{Yöntem}

Araştırmada, durum çalışması deseni kullanılmıştır. Nitel araştırma yöntemlerinden durum çalışması deseni, bir yahut birkaç duruma ilişkin etkenlerin derin bir şekilde araştırılmasını ve bu etkenlerin mevcut durum ile olan etkileşiminin incelenmesine imkan vermektedir (Yıldırım ve Şimşek, 2006: 73).

Araştırmanın çalışma grubunu amaçlı örnekleme yöntemi ile belirlenmiş, farklı meslek gruplarına mensup, UEFA Şampiyonlar Ligi organizasyonunu her müsabaka haftası, spor haberlerini ise haftada en az 4 gün takip eden ve bir futbol takımının taraftarı olan 11 erkek katılımc1 oluşturmaktadır. Araştırmaya dahil olan futbolseverlerin gerçek isimleri belirtilmemiş ve kendilerine "Mehmet, Rıza, Gökhan" gibi birer kod isim atanmıstır. Katılımcıların demografik bilgileri Tablo 1 'de yer almaktadir.

\section{Tablo 1. Kat1lımc1ların Demografik Bilgileri}

\begin{tabular}{ccccc} 
Katılımc1 & $\begin{array}{c}\text { Doğum } \\
\text { Y1lı }\end{array}$ & $\begin{array}{c}\text { Taraftarı Olunan } \\
\text { Takım }\end{array}$ & $\begin{array}{c}\text { Avrupa'da } \\
\text { Sempati } \\
\text { Duyulan Takım }\end{array}$ & Meslek \\
\hline Feyyaz & 2002 & Fenerbahçe & Barcelona & Öğrenci \\
\hline Kadir & 1996 & Fenerbahçe & Liverpool & Polis \\
\hline Gökhan & 1979 & Galatasaray & Barcelona & Gazeteci \\
\hline Recep & 1990 & Galatasaray & Barcelona & Memur \\
\hline Rıza & 1998 & Trabzonspor & Arsenal & Serbest meslek \\
\hline Mehmet & 1990 & Beşiktaş & Yok & Öğretmen \\
\hline Metin & 1997 & Göztepe & Yok & Sporcu \\
\hline Sergen & 1984 & Galatasaray & Real Madrid & Sağlık personeli \\
\hline Ali & 1991 & Beşiktaş & St. Pauli & Akademisyen \\
\hline Ulvi & 1989 & Ankaragücü & Yok & Isşçi \\
\hline Zeki & 1988 & Fenerbahçe & Lazio & Eczac1
\end{tabular}

Verilerin toplanması aşamasında, katılımcının araştırma konusuyla ilgili mevcut duruma ilişkin görüşlerini ve bakış açısını ortaya koymasına imkan sağlayan (Merriam ve Tisdell, 2015) yarı yapılandırılmış görüşme formu kullanılmıştır. Kavramsal çerçeveyi ve görüşme formunu hazırlamak amacıyla literatür taranmış ve iki alan uzmanının katkıları neticesinde beş sorudan oluşan yarı yapılandırılmış görüşme formu nihai haline ulaşmışır.

Örnek soru: UEFA'nm kulüpler bazundaki organizasyonlar ve uygulamalar bakkinda ne düş̈̈n̈̈yorsunuz?

Pandemi sebebi ile katılımcılardan veriler video konferans uygulaması aracilığı ile toplanmıştır. Katılımcıların onayı neticesinde görüşmeler kayıt altına alınmış ve sonrasında deşifre edilerek yazılı formata dönüştürülmüştür.

Veriler içerik analizi yöntemi ile çözümlenmiş ve bu noktada iç tutarlığın belirlenmesi amacı ile "Güvenirlik = Görüş birliği / (Görüş Birliği + Görüş Ayrllığı)" formülünden faydalanılmıştır (Miles ve Huberman, 1994). Bu doğrultuda araştırmanın iç tutarlık değerinin 0,80 olduğu görülmüştür. 


\section{Bulgular}

Bu bölümde, Avrupa Süper Ligi projesi ve paydaşlarına ilişkin katılımcıların görüşlerinden elde edilen veriler analiz edilerek sunulmuştur.

\section{Futbolun Değişimi ve Popülaritesi}

Kattlımcıların tamamı, futbolun son yıllarda hızla endüstriyelleşerek büyük bir değişim içerisinde olduğunu ve taşıdığı manevi etkenlerden çok maddi bir olgu haline geldiğini belirtmişlerdir.

Gökhan: "Futbolun eskiden bir rubu varde benim için. Günümüzde ișin içine bu kadar paranm girmesi o rubu öldürdü bence. Futbolcular da kulüpler de mekanik bir hal ald. O nedenle, alt liglerde tamamen amatör rubla oynanan müsabakalar bana daha çok keyif veriyor".

Ali: "Büyü̈ bir değişim var evet ancak bu kaçnlmaz, bir durum. Bu kadar ilgi gören, tüketilen bir spor branşımın içinde milyar dolarlar dönen bir sektör haline gelmesi çok normal. Dünya artık böyle, paranm etrafinda dönüyor. Buna karşı koyamažsımı̨".

Araştırma bulgularına göre katılımcıların bir kısmı futbolun popülaritesini korumaya devam ettiğini, bir kısmı ise futbola yönelik ilginin azaldığını ifade etmiştir.

Zeki: "Günümüzde imkanlar ve teknolojike, gelismeler artıkşa insanlar farkh spor branslarna erişsebiliyorlar. İzleyebiliyorlar, katilabiliyorlar. Ancak yine de sporu genel olarak düsünürsek futbolun yeri her zaman ayr bence. En çok ilgi gören, en çok takip edilen ne olursa olsun yine de futbol".

Rıza: "Takımma olan bağhlĭğm baki ancak bu șike olaylarn sonrasinda ben biraz. soğudum futboldan. Güvenim sarsildr. Maç değil de, senaryosu belli sonucu belli bir tiyatro oyunu ižliyormuşum gibi geliyor. Bir de bu espor olayn varyeni nesilde. Biz ailecek fanatik. Trabzonsporluyuz ancak yeğenlerim var mesela ergenlik çăğnda, sorsam kealecinin adm bilmezler. Varsa yoksa bilgisayar oyunlar".

\section{Futbolda Yapısal Değişim İhtiyacı}

Kattlımcıların, futbolda yapısal anlamda değişim ihtiyacına yönelik görüşleri incelendiğinde, köklü değişimlerden ziyade daha küçük eklemelerle gerçekleştirilmesi gerektiğine yönelik ifadeleri olduğu görülmektedir.

Ulvi: "Insanlarn yullardir alıștı̆̆ ve sevdiği bir futbol var. Kurallarla ya da diğer etkenlerle oynayarak bunu

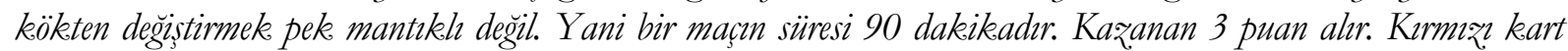
görürsen oyundan çıarsin. Bunlar net. Herkesin bildiüi futbol bu. O yüzden maceraya girmeye gerek yok.”.

Mehmet: "Her şeyin değisime ibtiyacı vardir. Doğann kanunu bu. Şartlara uyum sağlamak gerekir. Ancak. futbol gibi popüler ve bu haliyle kabul görmüs bir seyi tamamen değistirmek riskli. Daha ufak, ibtiyaca yönelik olursa amenna. Örneğin VAR sistemi. Hakem batalarm ve baksı̨lkelar minimuma indirmek adina șahane bir yenilik oldu. Sabi bizim ülkede bala pek beceremedik bu işi ama olsun”.

\section{Avrupa Süper Ligi Projesi}

Katllımciların Avrupa Süper Ligi’ne yönelik ifadelerinin çoğunlukla olumsuz olduğu tespit edilmiştir. Buna ek olarak, gerçekleşmemiş bir proje olmasının futbol adına sevindirici olduğu görüşü hakimdir. Yalnızca bir katılımcı ise söz konusu projeye yönelik olumlu bir yaklaşım sergilemiştir.

Metin: 'Bu ligi kurmak isteyen takımlara bakiyorum, e zaten Avrupa'nin en zenginleri ve imkanlar en

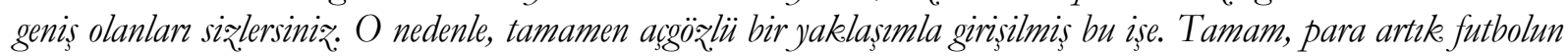
olmazsa olmaz̨ maalesef ama bu kadar da olmamal. Ben Göztepe taraftaryzm. En büyü̈k hayalim bir gün takımımın Şampiyonlar Ligine katulması ve orada en güçlü Avrupa takımlarm yenmesi. Bu proje gerçeklessseydi benim bayalim ne olacakt?? Siðlere ömür".

Recep: "Yani bu projenin basındakiler resmen diyorlar ki sizfakirler aramıda oynaym bize ilismeyin. Biz.

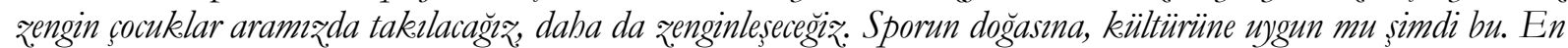
iyi futbolu oynayanlar veya en basarnl olanlar değil de en çok parası olanlar oynayacak o ligde, planlarna göre. Yok öyle yağma. Neyse ki beceremediler".

Ali: "Ben bu Avrupa Süper Ligi'ni hayata geçirmeye çalısanlarn kurumsal iletişim açısından ciddi bir stratejilk hata yaptiğna inanyyorum. Kendileri belki uұ̨n süredir bu projeyi planlyyorlardır, açılamalar öyle takip ettiğim kadarryla. Ama bunu taraftara, futbolsevere öyle tepeden inme, biz yaptık oldu seklinde dayatrrsanz ciddi 
Ötkan, C. C.., \& Çolakoğlu, T. (2021). Futbolda güç savaşları: Avrupa Süper Ligi Projesi ve etkileri. Journal of Human Sciences, 18(3), 485-496. doi:10.14687/jhs.v18i3.6198

tepki çekersiniæ: Ki öyle oldu. Bu projeyi ve dertlerini bir sürece yayarak. futbolsevere anlatsalard sonuc farkl olurdu belki, bilemiyorum. Benim yaklaşımım yine olumsuz, olurdu, o ayr".

Ulvi: "En çok Real Madrid basskanmm açklamalarm bayretler içerisinde takip ettim. Neymis, büyüke borçlar varmıs, batak durumundalarmıs, A vrupa futbolunu ancak bu proje kurtarrmış. E kardeșim ben mi dedim sana sakatlkktan çıkamayan futbolcuya 100 milyon Euro ver diye, ben mi dedim her sene sattı̆̆ndan fazlasin al diye. Kötü bir yöneticisin demek ki”.

Yukarıda yer verilen ifadelerde katılımcıların çeşitli nedenlerle Avrupa Süper Ligi'ne olumsuz yaklaşım sergiledikleri ve bir futbolsever ve taraftar olarak desteklemedikleri görülmektedir. Araştırmanın çalışma grubundaki 20 yaş altı tek katılımcı olan Feyyaz ise söz konusu projeye olumlu yaklaştı̆̆ını şu şekilde ifade etmiştir:

Feyyaz: "Fanatik Fenerbahçeliyim. Ama inann Türkiye ligini į̧lerken ac cekiyorum. Şampiyonlar Ligi yine bir nebze kaliteli ancake orda da grup aşamast ile sonraki assamalar arasinda ciddi bir seyir zevki farke var. E bu lig ne vaat ediyor bize? En çok parası olan ve doğal olarak en kaliteli kadrolara sabip takımlarm birbirleriyle her hafta mas yapacağm vaat ediyor. Düsünsenize, her hafta Barcelona, Manchester City, Liverpool ve Juventus gibi takımlar aralarnda mas yapacaklar. Ben bir futbolsever olarak neden bunu istemeyeyim ki. Neymis sadece parast olanlar oynayacakmıs olmazmıs. E mevut düzende sanki parası olmayan ne kadar rekabet edebiliyor, ne kadar başarli olabiliyor".

\section{UEFA ve Taraftarın Avrupa Süper Ligi Projesine Yaklaşımı}

Avrupa Süper Lig projesine karşı UEFA'nın ve taraftarın yaklaşımına yönelik araştırmada yer alan kattlımcıların görüşleri incelenmiştir. Bu doğrultuda, tupkı UEFA gibi söz konusu projeye karş1 olan katulımcıların dahi UEFA'nın söylem ve aksiyonlarını onaylamadığı görülmektedir.

Ulvi: "Haberleri yakundan takip ettim, merak da ettim bakalum ne olacak diye. UEFA Baskan panike oldu hemen, çıtı esti gürledi. Niye? Kendi gücleri ellerinden alnacak, cepleri dolmayacak da ondan. Futbolu çok sevdiklerinden ya da biz, taraftarn karakaşina kara göəzüne değil. Samimi değiller. Ama o protestolar düzenleyen taraftar samimi bak. Sonuna kadar da haklhlar. Cü̈nkü dediler ki futbolun sabibi birį kardeşim. Ben stada gelmezsem, forman atkem montunu her seyini satm almazsam sen nasil vereceksin o paralar futbolculara. Kim ciddiye alacak o zaman seni".

Kadir: "Sosyal medyada çok fąla vakit geçiren bir futbolseverim. Ana akım medyada asla göremeyeceğimiz. pek sok habere orda erişiliyor. O mecrada çok sik rastladiğm bir ifade var şu şekilde; UEFA-MAFLA. Acr ama gercek. Bölle bir alg var pek çok insanda ve bende. Seffaf değiller, taribleri skandallarla dolu ve futbola zarar veriyorlar. O nedenle, bu projeye ben de karssyım fakat UEFA da karsı diye düsmanımn düsman dostumdur divemeyeceğim bu durumda".

Ali: "UEFA tamamen otoritesini ve statïkoyu korumak adına ilk andan itibaren karşı çıtı Avrupa Süper Ligi'ne. Bunun dişındaki tüm açılamalar bir bikayeden ibaret. Ama bu projeyi iptal ettiren UEFA'nnn tehditleri olmadı bence. Oraya katılan takımlar bunlar zaten göze almıs ve planlamışlardır diye düsünüyorum. Avrupa Süper Ligi projesini iptal ettiren tamamen taraftarn tepkisidir, şahsi kanaatim”.

\section{UEFA'nın Uygulamaları: Yeni Şampiyonlar Ligi Formatı ve Finansal Fair Play (FFP)}

UEFA'nın Avrupa Süper Ligi projesi ile belli noktalarda ilişkisi bulunan yeni Şampiyonlar Ligi formatı FFP uygulamalarına yönelik katılımcıların görüşlerinden elde edilen bulgular incelenmiştir.

Yeni Şampiyonlar Ligi formatına ilişkin katılımc ifadeleri şu şekildedir:

Sergen: 'Yeni Şampiyonlar Ligi formatında takım ve mas sayısı artt. UEFA'nun savunduğu kapsayıc yaklassıma uygun ancak bunun Avrupa Süper Ligi projesini tasarlayan kulïpleri pek de memnun edeceğini sanmyyorum. Çünkü onlar, zaynf takımlarla yaptıklar maçlar angarya olarak görïyorlar. Bu nedenle önümüzdeki yullarda bu projeyi tekrar denerlerse șasirmam".

Gökhan: "Ben bu yeni format hakkenda biraz, kararsız, kaldım, iyi mi olacak kötü mü bilemedim. Takem sayısı artnca, görece zaynf kulüplerin bu organizasyonda sürpriұ̨ler yapmalar, güzel bikayeler yazmalar iyi olabilir.

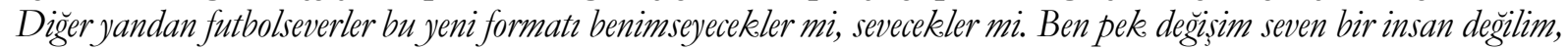
belki de o yüzden kararsı kealmişımder". 
Ötkan, C. C.., \& Çolakoğlu, T. (2021). Futbolda güç savaşları: Avrupa Süper Ligi Projesi ve etkileri. Journal of Human Sciences, 18(3), 485-496. doi:10.14687/jhs.v18i3.6198

Katllımcıların FFP ve Avrupa Süper Ligi projesi arasındaki ilişkiye yönelik görüşlerine ise aşağıda yer verilmiştir.

Mehmet: 'FFP güzel ve faydah bir uygulama bence ama eksik. Örneğin gelirin kadar harca diyor tamam ama A takımmm var 500 milyon Euro geliri, B takımmm var 50 milyon Euro geliri. Bu aradaki makasi kapatmak. için de bir seyler yapulabilir. Örneğin yülkse gelire sabip kulüpler belli bir miktarda kotasinı așthğı zaman bu bir yerde toplamip, kotasm asmayan dar gelirli kulüplere dağttlabilir. Rekabet de artacaktır bence o zaman".

Rıza: 'Tamamen gereksiz, olarak görüyorum ben FFP'yi. UEFA bununla uğraşacağma desin ki, fermanmmdir kulüplerin hepsi șirketleșecek, sermaye sahipleri yönetecek takımlar. Bizdeki gibi dernek vs. olmayacak. $O$ zaman kimse zaten har vurup harman savurmaz olmayan paralar. Adam sermaye koymus ortaya, zarar etmek ister mi".

Zeki: "Bizim Türk takımlarn sürekli sorun yasaynnca bu FFP ile ilgili, merak ettim ve detayluca arasttraynm dedim. O esnada dikkeatimi cekti, kulüp baskean ya da yöneticiler belli bir miktarda para aktarabiliyor kulübe. Sonrası gelirden saynlmyyor. Böyle bir șey örneğin çok parası olan Manchester City gibi takımlar rahatsız etmişstir. Kaynak aktarmi sinirlanyyor çünkü”.

\section{Tartışma ve Sonuç}

Farklı meslek gruplarından 11 futbolseverin katılmış olduğu bu araştırmada Avrupa futbolunda yaşanan güç savaşları, futbolun değişimi-Avrupa Süper Ligi-UEFA üçgeninde ele alınmış ve incelenmiştir.

Futbolun değişimi ve popülaritesine ilişkin bulgulara bakıldığında, günümüzde artık çok daha endüstriyel bir karaktere bürünmüş olduğu ve bu durumun git gide daha da güçlendiği bir yapının ortaya çıktı̆ı görülmektedir.

Avrupa futbolunda pek çok takımın şirket bünyesi altında faaliyetlerini yürüterek gerek kıta gerek kıta dışından sermayedarlara sahip olmaları ve dünya çapında farklı piyasalarda işlem görmeleri araştırma bulgusunu destekler niteliktedir (Gómez-Martínez, Prado-Román ve Menéndez Moreno, 2017; Chen, Dietl, Orlowski ve Zheng, 2019).

Buna ek olarak, aralarında Türkiye'den Galatasaray ve Trabzonspor'un da bulunduğu Barcelona, Manchester City ve Paris Saint-Germain gibi farklı Avrupa kulüpleri kendi 'Taraftar Token'larını piyasaya sürmüş ve kripto para borsalarında işlem görmeye başlamışlardır (Devecioğlu, 2020). Bu durum da, futbolun artık sadece sahada oynanan bir oyun olmadığını göstermektedir.

Z Kuşağı erkekleri üzerine yapılan bir araştırmada katllımcıların, futbol gibi geleneksel sporlardan daha çok e-spor gibi geleneksel olmayan spor branşlarına ilgi duydukları tespit edilmiştir (Sweeney, 2018). Benzer şekilde Avrupa Süper Ligi projesinin kurucularından olan Florentino Perez; 14-24 yaş aralığındaki bireylerin futbola olan ilgi düzeyinde düşüş olduğunu belirtmiştir (Maroto, 2021). Özellikle e-sporun yükselişi ve yeni nesilden gördüğü ilgiye rağmen (Kim, Nauright ve Suveatwatanakul, 2020), araştırmada yer alan katılımcılar futbolun popülaritesini ve zirvedeki yerini koruduğunu ifade etmişlerdir. Buna ek olarak, futbolun yapısal olarak köklü değişimlere ihtiyaç duymadığını belirtmişlerdir. Maç süresinin kısaltılması veya kurallarda köklü değişiklerdense VAR (Video Assistant Referee) gibi oyunun gelişimine katkı sağlayacak ancak dokusunu bozmayacak değişimlerin olması gerektiğini öne sürmüşlerdir.

Araştırmanın çalışma grubuna dahil 11 katılımcıdan yalnızca bir kişi Avrupa Süper Ligi projesine yönelik olumlu görüş belirtmiş, diğer katılımcıların tamamı projeye yönelik olumsuz yaklaşımda bulunmuşlardır. Avrupa Süper Ligi projesindeki katılım kriterlerinde sportif başarıdan ziyade maddi kaynakların göz önünde bulundurulmasını eleştiren katılımcılar, bu şekilde liyakatin esas alınmadığı kapalı bir ligin benimsedikleri spor kültürüne aykırı olduğunu belirtmişlerdir. Buna ek olarak, Avrupa Süper Ligi’nde yer alan kurucu kulüplerin, taraftarlarıyla sağllklı bir iletişim kurmadan ve fikir almadan böyle bir projeye dahil olmalarının önemli bir kurumsal iletişim hatası olduğunu ve bunun projenin akıbetini olumsuz etkilediğini ifade etmişlerdir.

Akşar (2021b) da, söz konusu projedeki kurucu kulüplerin, taraftarın tercih ve düşüncelerinin arka plana iterek onları yalnızca tüketici olarak gördüklerini belirtmiş, projenin futbolseverler ile doğru bir iletişim kuramadığını ve alternatif planlar üretemediğini ifade etmiştir. 
Avrupa Süper Ligi projesine olumlu yaklaşım sergileyen katılımcı ise, mevcut UEFA organizasyonlarında yüksek profilli maç sayısının düşük olduğunu, böyle bir proje sayesinde her hafta seyir zevki yüksek futbol müsabakaları izleme imkanı yakalayacağını belirtmiştir.

Macey-Dare (2021) çalışmasında, futbolun geldiği nokta ve geleceği açısından küresel hüviyete sahip ve en iyi olarak nitelendirilen takımların Avrupa Süper Ligi gibi bir oluşum dahilinde, daha fazla izlenen ve daha fazla para kazanan bir modele ihtiyaç duymasının kaçınılmaz olduğunu belirtmiştir.

UEFA ve taraftarların Avrupa Süper Ligi’ne yönelik tutumu, projenin iptalindeki en büyük etkenler olarak görülmektedir. Bu noktada araştırma bulgularına göre; UEFA'nın projeye yönelik tepkisinin futbolu ve taraftarı önemsemekten ziyade kendi otoritesini korumaya yönelik olduğu, mevcut olumsuz durumdan sorumlu olduğu, bu nedenle de samimi ve inandırıcı olmadığına yönelik görüssler tespit edilmiştir. Avrupa Süper Ligi’ne yönelik taraftar tepkilerine ise katılımcıların olumlu yaklaştı̆̆1 ve projenin iptalini UEFA'nın yaptırım tehditlerinden daha çok futbolseverlerin protestolarının sağladığı bulgusuna ulaşılmıștır.

Avrupa Süper Ligi’nden ayrılan kulüp sahiplerinin açıklamaları, araştırma bulgularını destekler niteliktedir. Kulüp sahipleri, mevcut sistemde sorunlar olduğunu ve bu nedenle ekonomik anlamda daha sürdürülebilir bir organizasyona dahil olarak takımlarının geleceğini düşündüklerini ancak taraftar desteği olmadan gerçekleştirdikleri bu eylem için gelinen noktada tüm taraftarlarından özür dilediklerini belirtmişlerdir (Jackson, Ames ve Hunter, 2021).

UEFA Şampiyonlar Ligi'nin mevcut format1, Avrupa Süper Ligi'nin kurucuları tarafindan eleştirilen bir nokta olarak karşımıza çıkmaktadır. Bu nedenle araştırma kapsamında katılımcıların yeni Şampiyonlar Ligi formatına ilişkin görüşleri alınmıştır. Yeni formatla birlikte takım ve maç sayısının artacağı ancak yine de ilk aşamadaki müsabakaların yüksek profilli olmayacağı, bu nedenle de Avrupa Süper Ligi projesine dahil olmak isteyen kulüplerin bu durumdan memnun olmayabileceği ifade edilmiştir. Bunun sonucunda da ilerleyen yıllarda tekrar ayrllıçı bir girişimin gerçekleşebileceği öngörülmektedir. Diğer yandan, takım sayısının artması ile sürprizlere ve romantik futbolseverler için yeni futbol hikayelerine daha elverişli bir organizasyon olabileceği belirtilmiştir.

Johnson (2021) ise, Şampiyonlar Ligi'nde her bir maçın kulüpler için ciddi maddi getirisi olduğunu, yeni format sayesinde ilk aşamada yapılacak 6 maçın 10 olacağını ve bu durumun da kulüplere daha fazla getiri sağlayacağını belirtmiştir. Bu durumda, ilk aşamalardan itibaren yüksek profilli müsabakalar oynamak isteyen kulüplerin beklentisi yerine getirilemese de, futbolu yalnuzca para olarak gören takım sahiplerinin artan maç sayısına bağlı gelir artışına olumlu yaklaşacakları düşünülebilir.

UEFA'nın uygulamaları ile Avrupa Süper Ligi oluşumu arasında bir kesişim kümesi olarak görülen bir diğer olgu ise Finansal Fair Play uygulamasıdır. Araştırma bulgularına göre, FFP’ye yönelik farklı görüşler tespit edilmiştir. Uygulamanın teoride faydalı ancak uygulamada eksik olduğu, kulüplerin gelir düzeyleri arasındaki makasın fazlasıyla açı olduğu ve FFP aracıllğı ile bu makasın daraltılarak rekabeti artırması gerektiği ifade edilmiştir. Diğer bir görüşe göre ise FFP uygulamasının gereksiz olduğu, bunun yerine dernek statüsünde faaliyet gösteren kulüplerin sermayedarlar tarafından şirket modeli ile yönetilmesi durumunda FFP'nin çözmeyi amaçladığı sorunların ortadan kalkabileceği belirtilmiştir. Buna ek olarak, Avrupa Süper Ligi kurucuları arasında da yer alan ve maddi kaynakları oldukça yüksek olan kulüplerin FFP uygulamasından harcamalarını ve arzu ettikleri sportif hamleleri kısıtlaması açısından rahatsız olabilecekleri, bu nedenle de Avrupa Süper Ligi'nin oluşturacağı maddi dinamiklerin kendilerine daha cazip gelmiş olabileceği görüşü ortaya konmuştur.

Paris Saint-Germain, Manchester City ve Chelsea'nin FFP kuralların ihlal nedeni ile UEFA tarafindan sorgulamaya alınarak yaptırımlara maruz kalmış olmaları (Maroto, 2019), araştırma bulgusunu destekler nitelikte olarak görülmektedir. Buna ek olarak Akşar (2021a), projede bulunan kulüplerin neden Şampiyonlar Ligi organizasyonun ayrllmak istediğini açıklarken, söz konusu kulüplerin marka değerine sağladıkları katkılar nedeni ile UEFA'dan FFP uygulaması konusunda tavizler almayı planladıklarını belirtmiştir.

Avrupa futbolundaki güç savaşı şu an için UEFA'nın lehine sonuçlanmış görünmekte ve 'The Super League' varlığını hayalet olarak sürdürmektedir. Ancak araştırma bulguları bize, UEFA'nın bu 
zaferinin geçici olabileceğini ve süregelen sorunların, bildiğimiz futbolun geleceğini tehdit ettiğini göstermektedir. Futbol kulüplerinin ise, hangi iş modelini kurarsa kursun, hangi organizasyona dahil olursa olsun öncelikle arkasına taraftar desteğini almayı düstur edinmesinin faydalarına olacağı düşünülmektedir. Araşturmanın konusu kapsamında incelenen süreç bize göstermektedir ki, son sözü milyarder kulüp sahipleri değil, taraftar söylemektedir.

\section{Kaynaklar}

Akşar, T. (2021a, 6 Mayıs). Avrupa Süper Ligi: Artık Hiçbir Şey Eskisi Gibi Olmayacak! Futbol Ekonomisi \& Endüstriyel Futbol. https://cutt.ly/CnwZnTk (Erişim tarihi: 24.05.2021).

Akşar, T. (2021b, 11 Mayıs). Avrupa Süper Ligi Oluşumunun Arka Planında Neler Var? Dünya. https://cutt.ly/7nHEboL (Erişim tarihi: 13.06.2021).

Chen, Y., Dietl, H. M., Orlowski, J., \& Zheng, F. (2019). The Effect of Investment into European Football on the Market Value of Chinese Corporations. International Journal of Sport Finance, 14(4), 249-261. Doi: 10.32731/IJSF/144.112019.05

Davies, G. (2021, 20 Nisan). European Super League Announcement Sends Shockwaves Through Global Soccer. Abc News. https://cutt.ly/vb1Jm1D (Erişim tarihi: 12.05.2021).

Devecioğlu, S. (2020, 2 Aralık). Futbolda Token Piyasas1. Futbol Ekonomisi \& Endüstriyel Futbol. https://cutt.ly/nnFRURa (Erişim tarihi: 13.06.2021).

Gómez-Martínez, R., Prado-Román, C., \& Menéndez Moreno, R. (2017). Investing in Shares of Europe Football Clubs: Definitely, an Alternative Investment. Sports Management as an Emerging Economic Activity, 183-192. Doi:10.1007/978-3-319-63907-9_11

Hill, G. A. (2021, 8 Mayıs). UEFA Reintegrates Nine of 12 Super League Teams; Holdouts Could Face Disciplinary Measures. The Washington Post. https://cutt.ly/dnwXflL (Erişim tarihi: 24.05.2021).

Jackson, J., Ames, N., \& Hunter, A. (2021, 21 Nisan). Manchester United and Liverpool Plead for Forgiveness for Super League Fiasco. The Guardian. https://cutt.ly/0nKRLS2 (Erişim tarihi: 14.06.2021).

Jonhson, D. (2021, 23 Nisan). Champions League Swiss Model Revamp: All You Need to Know. ESPN. https://cutt.ly/mKYJ02 (Erişim tarihi: 15.06.2021).

Kim, Y. H., Nauright, J., \& Suveatwatanakul, C. (2020). The Rise of E-Sports and Potential for PostCOVID Continued Growth. Sport in Society, 23(11), 1861-1871.

Leading European Football Clubs Announce New Super League Competition (t.y). The Super League Resmi Web Sitesi. https://thesuperleague.com/press.html (Erişim tarihi: 13.05.2021).

Macey-Dare, R. (2021). A League of Their Own-Logic of the Super League. Available at SSRN 3830436.

Maroto, J. (2019, 23 Şubat). Chelsea Case: Manchester City and PSG Next Up for UEFA. As. https://cutt.ly/UnKIEtK (Erişim tarihi: 16.06.2021).

Maroto, J. (2021, 24 Nisan). Florentino Pérez: "Either We Do Something Soon or A Lot of Clubs Will Go Bankrupt". As. https://cutt.ly/kb2Nhqg (Erişim tarihi: 17.05.2021).

Merriam, S. B., \& Tisdell, E. J. (2015) Qualitative Research: A Guide To Design And Implementation. San Francisco : John Wiley \& Sons.

Miles, M. B., \& Huberman, A. M. (1994). Qualitative Data Analysis: An Expanded Sourcebook (Second Edition). Thousand Oaks: Sage.

Müller, J. C., Lammert, J., \& Hovemann, G. (2012). The Financial Fair Play Regulations of UEFA: An Adequate Concept to Ensure the Long-Term Viability and Sustainability of European Club Football?, International Journal of Sport Finance, 7(2), 117-140.

New Format for Champions League Post-2024: Everything You Need to Know (2021, Nisan 20). UEFA Champions League Resmi Web Sitesi. https://cutt.ly/tb9qPgx (Erişim tarihi: 20.05.2021). 
Özkök, H. (2021, 27 Nisan. Avrupa Süper Ligi: İskambil Kağıdından Yapılan Ev Yıkıldı. Futbol Ekonomisi \& Endïstriyel Futbol. https://cutt.ly/BnwCbSf (Erişim tarihi: 24.05.2021).

Super League Clubs 'Will Be Held Responsible' (2021, 25 Nisan). The Atbletic. https://cutt.ly/kb2V8D1 (Erişim tarihi: 19.05.2021).

Sweeney, E (2018, 18 Ekim). Study: 52\% of Gen Z Males Prefer Nontraditional Sports. Marketing Dive. https://cutt.ly/znFIG0m (Erişim tarihi: 13.06.2021).

Szymanski, S. (2014). Fair Is Foul: A Critical Analysis of UEFA Financial Fair Play. International Journal of Sport Finance, 9(3), 218-229.

Vöpel, H. (2013). Is Financial Fair Play Really Justified? An Economic and Legal Assessment of UEFA's Financial Fair Play Rules. Hamburg Institute of International Economics, Policy Paper (No. 79).

Yıldırım, A., \& Şimşek, H. (2006). Sosyal Bilimlerde Nitel Araştırma Yöntemleri. (10. Baskı). Ankara: Seçkin.

\section{Extended English Summary}

\section{Introduction}

The project, which was launched as the European Super League in the Turkish press and whose original name was 'The Super League', was announced to the public by 12 founding clubs on April 18, 2021. Founding clubs; It appears as AC Milan, Arsenal FC, Atlético de Madrid, Chelsea FC, FC Barcelona, FC Internazionale Milano, Juventus FC, Liverpool FC, Manchester City, Manchester United, Real Madrid CF and Tottenham Hotspur (Davies, 2021).

In the project planning, it was aimed to increase the number of founding clubs to 15 and then to include 5 more football teams in the league and to realize the competitions. It has been stated that approximately 3.5 billion Euros will be transferred to the founding clubs as a down payment with the financial support of JP Morgan. In addition, it is aimed that the organization will progress as weeklong competitions within the scope of the August-May calendar, have a closed league format, and that the participating clubs will continue their organizations in their local leagues ("Leading European Football Clubs Announce New Super League Competition", 2021).

It is seen through this information that; The organization was established as an alternative to the Champions League, which is considered the most popular football event on the basis of clubs. This situation has led to various reactions from both UEFA and different subjects of football.

\section{Purpose}

It is thought that the opinions of football fans about the European Super League project, UEFA's activities and the power struggles are important, and it is aimed to bring them to the literature by researching them based on this importance.

\section{Method}

In the research, case study design was used. The case study design, which is one of the qualitative research methods, allows the factors related to one or more situations to be investigated in depth and the interaction of these factors with the current situation (Yildırım and Şimşek, 2006: 73).

The study group of the research consists of 11 male participants, who are determined by the purposeful sampling method, belong to different occupational groups, follow the UEFA Champions League organization every competition week and sports news at least 4 days a week and are fans of a football team. The real names of the football fans included in the research were not specified and a code name such as "Mehmet, Rıza, Gökhan" was assigned to them.

At the stage of data collection, a semi-structured interview form was used, which allows the participant to reveal his views and perspective on the current situation on the research topic (Merriam 
Ötkan, C. C.., \& Çolakoğlu, T. (2021). Futbolda güç savaşları: Avrupa Süper Ligi Projesi ve etkileri. Journal of Human Sciences, 18(3), 485-496. doi:10.14687/jhs.v18i3.6198

and Tisdell, 2015). In order to prepare the conceptual framework and the interview form, the literature was surveyed and the semi-structured interview form consisting of five questions reached its final form as a result of the contributions of two domain experts.

The data were analyzed with the content analysis method, and at this point, the formula "Reliability = Agreement / (Agreement + Disagreement)" was used to determine the internal consistency (Miles and Huberman, 1994). Accordingly, the internal consistency value of the study was found to be 0.80 .

\section{Results}

All of the participants stated that football has rapidly industrialized in recent years and has undergone a great change and has become a material phenomenon rather than its spiritual factors.

Gökhan: "Football used to have a soul for me. I think that much money killed that spirit. Football players and clubs have become mechanical. Therefore, competitions played in the lower leagues with an amateur spirit give me more pleasure".

According to the research findings, some of the participants stated that football continues to maintain its popularity, while some stated that the interest in football decreased.

Zeki: "Today, as opportunities and technological developments increase, people can access different sports branches. They can watch, they can participate. However, if we think about sports in general, I think football always has a different place. Regardless of what attracts the most attention and is followed the most, it is still football".

When the opinions of the participants on the need for structural change in football are examined, it is seen that they express that it should be done with smaller additions rather than radical changes.

Mehmet: "Everything needs change. This is law of nature. However, it is risky to completely change something as popular and accepted as football. It's ok if it's needed. For example, Video Assistant Referee. It was a wonderful innovation in order to minimize referee mistakes and injustices".

It was determined that the opinions of the participants about the European Super League were mostly negative. In addition, there is a dominant opinion that the fact that it is an unrealized project is pleasing for football. Only one participant showed a positive approach towards the project.

Ali: "T believe that The Super League made a serious strategic mistake in terms of corporate communication. Maybe they have been planning this project for a long time, but if you impose this on football fans, you will get serious reactions. That's how it happened. If they had explained this project to football fans in a wider process, maybe the result would have been different".

The opinions of the participants in the research were examined regarding the approach of UEFA and the fans towards the European Super League project. In this direction, it is seen that even the participants who are against the project, just like UEFA, do not approve of UEFA's discourse and actions.

Ali: "UEFA opposed the European Super League from the very first moment in order to preserve its authority and status quo. All other explanations are just a story. But I think there were no threats from UEFA that canceled this project. I think that the teams participating there have already taken these into considerations and planned. It is the reaction of the fans that canceled the European Super League project, in my personal opinion".

The findings obtained from the opinions of the participants on the new Champions League format and FFP, which are related to UEFA's European Super League project at certain points, were examined.

Sergen: "The number of teams and matches has increased in the new Champions League format. It is in line with UEFA's inclusive approach, but I don't think this will please the clubs that designed the European Super League project. Because they see the matches they play with weak teams as a drudgery. That's why I wouldn't be surprised if they try this project again in the coming years".

A participant's opinion on the relationship between FFP and the European Super League project is as follows:

Mehmet: "I think FFP is useful, but it is incomplete. For example, it says spend as much as your income, but team A has 500 million Euro income, B team has 50 million Euro income. In the meantime, something can be 
done to close the gap. For example, when high-income clubs exceed their limit by a certain amount, it can be collected in one place and distributed to low-income clubs that do not exceed their limit. Then I think the competition will increase as well".

\section{Discussion and Conclusion}

When we look at the findings on the change and popularity of football, it is seen that today it has taken on a much more industrial character and this situation is getting stronger.

The fact that many teams in European football carry out their activities under the company, have both continental and non-continental investors and are traded in different markets around the world supports the research findings (Gómez-Martínez, Prado-Román and Menéndez Moreno, 2017; Chen, Dietl, Orlowski, and Zheng, 2019).

In a study on Generation Z males, it was determined that the participants were more interested in non-traditional sports branches such as e-sports than traditional sports such as football (Sweeney, 2018). Particularly, despite the rise of e-sports and the interest it has received from the new generation (Kim, Nauright and Suveatwatanakul, 2020), the participants in the research stated that football maintains its popularity and its place at the top. In addition, they stated that football does not need fundamental changes in its structure. They argued that instead of shortening the match time or radical changes in the rules, there should be changes such as VAR that will contribute to the development of the game but will not disrupt its texture.

The participants stated that the European Super League project was contrary to the sports culture they adopted. In addition, they stated that it was an important corporate communication error for the founding clubs in the European Super League to be included in such a project without getting advice from their supporters. Akşar (2021b) also stated that the clubs involved in the project do not care about the preferences and opinions of the fans and see them only as consumers.

UEFA and the attitude of the fans towards the European Super League are seen as the biggest factors in the cancellation of the project. At this point, according to the research findings; It has been determined that UEFA's reaction to the project is to protect its own authority rather than caring about football and fans, it is responsible for the current negative situation, and therefore it is not sincere and convincing. Club owners stated that there are problems in the current system and therefore they think that their team will be involved in a more economically sustainable organization, but they apologized to all their fans for this action they took without the support of fans (Jackson, Ames and Hunter, 2021).

As a result, UEFA has won the power struggle in European football for the time being. However, research findings show us that this victory of UEFA may be temporary and ongoing problems threaten the future of football. On the other hand, it is thought that it will be beneficial for football clubs to take the support of fans first, no matter what business model they set up and which organization they are involved in. The process examined within the scope of the research shows us that the last word is said by the fans, not the billionaire club owners. 